\title{
Expression of interleukin-23 and its receptors in human squamous cell carcinoma of the oral cavity
}

\author{
MASAKATSU FUKUDA, MASAHIRO EHARA, SEIJI SUZUKI and HIDEAKI SAKASHITA \\ Second Division of Oral and Maxillofacial Surgery, Department of Diagnostic and Therapeutic Sciences, \\ Meikai University School of Dentistry, Saitama 350-0283, Japan
}

Received June 30, 2009; Accepted September 18, 2009

DOI: 10.3892/mmr_00000223

\begin{abstract}
Interleukin (IL)-23 is a heterodimeric cytokine comprising IL-12p40 and the recently cloned IL-23-specific p19 subunit. Like IL-12, IL-23 is expressed predominantly by activated dendritic cells and phagocytic cells. Both cytokines induce interferon- $\gamma$ secretion by $\mathrm{T}$ cells, and antagonistically regulate local inflammatory responses in the tumor microenvironment as well as the infiltration of intraepithelial lymphocytes. Although the expression of IL-23 in various organs has been reported, it is unclear whether IL-23 is expressed in oral cancer. The expression of IL-23 and its receptors was examined in human oral squamous cell carcinoma (HOSCC) cell lines and tissue. IL-23 and its receptor mRNAs and proteins were spontaneously expressed, and IL-23 was increased by TNF- $\alpha$ stimulation in the oral cancer cells. A cell proliferation assay confirmed that IL-23 promotes cell proliferation in oral cancer. The localization of IL-23 protein in HOSCC tissue was examined using immunohistochemistry. A positive reaction for anti-IL-23 antibody was weakly observed in the cytoplasm of inflammatory infiltrating cells and cancer cells in HOSCC tissue. Meanwhile, nuclear factor- $\kappa \mathrm{B}$ immunoreactivity was strongly positive in HOSCC tissue, which is particularly consistent with the observation of IL-23-positive cells in SCC tissue. These data suggest that IL-23 plays a significant role in the growth and proliferation of oral cancer.
\end{abstract}

\section{Introduction}

The epidemiologic relationship between cancer and inflammation has been well established. Many cancers arise at the site of chronic inflammation, and inflammatory mediators are often produced in tumors $(1,2)$. The frequent use of anti-

Correspondence to: Dr Masakatsu Fukuda, Second Division of Oral and Maxillofacial Surgery, Department of Diagnostic and Therapeutic Sciences, Meikai University School of Dentistry, 1-1 Keyakidai, Sakado, Saitama 350-0283, Japan

E-mail: fukudam@dent.meikai.ac.jp

Key words: interleukin-23, nuclear factor-кB, human oral squamous cell carcinomas inflammatory drugs reduces the incidence of a variety of human tumors (3). Although the blockade of certain of these mediators has been shown to be efficacious in experimental settings, it is still unclear whether the inflammatory reaction at the tumor site promotes tumor growth or simply indicates the failed attempt of the immune system to eliminate the rising malignancy. Cytokines comprise a large family of secreted proteins that bind to and signal through defined cell surface receptors on a wide variety of target cells, thus playing a pivotal role in the establishment and maintenance of homeostasis. Many cytokines share structural features and functions during development, immune response or inflammation.

Interleukin (IL)-23 is a heterodimeric cytokine with many similarities to IL-12 that was discovered during a structurebased bioinformatics search for novel IL-6 family members (4). IL-23 comprises a p19 subunit that associates with the IL-12p40 subunit (4), whereas IL-12 is a combination of IL-12p35 and the same IL-12p40 subunit (5). Furthermore, IL-23p19 is a molecule structurally related not only to IL-6, but also to granulocyte-colony stimulating factor (G-CSF) and the p35 subunit of IL-12. Although p19 is expressed in various tissues and cell types, it lacks biological activity and only becomes biologically active when complexed with p40, which is normally secreted by activated macrophages and dendritic cells (DCs) (4). IL-23 uses many of the same signaltransduction components as IL-12, including the IL-12 receptor (R) $\beta 1$ subunit (IL-12R $\beta 1$ ), Janus kinase (Jak)2, tyrosine kinase (Tyk)2, signal transducer and activator of transcription (Stat)1, Stat3, Stat4 and Stat5 (4,6). IL-23R, composed of the IL-12R $\beta 1$ and IL-23R subunits, is also expressed in DCs, macrophages and $\mathrm{T}$ cells (6). Consistent with the structural and biological similarities between IL-12 and IL-23, the IL-23R complex shares a subunit with IL-12 (IL-12R $\beta 1$ ); however, it does not use or detectably bind to IL-12R $\beta 2$ (4). The ability of cells to respond to IL-12 or IL-23 is determined by the expression of IL-12R $\beta 2$ or IL-23R, respectively (6). Additionally, both cytokines promote the T helper cell type 1 (Th1) costimulatory function of antigen-presenting cells (7). However, IL-23 does differ from IL-12 in the T cell subsets that it targets. IL-12 acts on naive CD4-positive T cells, whereas IL-23 preferentially acts on memory CD4-positive T cells (7). It has been reported that IL-12 has potent antitumor activity in a variety of murine tumor models, causing the regression of established tumors (8-10) and inhibiting the formation of 
experimental metastases $(8,9)$ and spontaneous metastases $(11,12)$. On the other hand, it was recently reported that genetic deletion or antibody-mediated elimination of IL-23 in mice leads to increased infiltration of cytotoxic $\mathrm{T}$ cells into the transformed tissue, rendering a protective effect against chemically-induced carcinogenesis (13). Although IL-23 and its receptors are expressed by activated macrophages, DCs and keratinocytes in healthy skin, it is largely unknown whether they are expressed in human oral cancer cells.

The present study investigated whether IL-23 and its receptors are expressed in human oral squamous cell carcinoma (HOSCC) in vitro and in vivo. IL-23 and its receptors were demonstrated to be spontaneously expressed, and IL-23 was increased by TNF- $\alpha$ stimulation in the oral cancer cells. Furthermore, a cell proliferation assay confirmed that IL-23 promotes cell proliferation in oral cancer. The expression and distribution of IL-23 and nuclear factor- $\kappa \mathrm{B}(\mathrm{NF}-\kappa \mathrm{B})$ was also examined in the HOSCC tissues.

\section{Materials and methods}

Reagents. Mouse anti-human NF-кB p65/RelA (p65) monoclonal antibody (MAb RelA) and goat anti-human IL-23p19 polyclonal antibody (PAb IL-23p19) were purchased from Santa Cruz Biotechnology (Santa Cruz, CA, USA) for immunoblot analysis and immunohistochemistry. MAb IL-23R and MAb IL-12R $\beta 1$ were purchased from R\&D Systems (Minneapolis, MN, USA). MAb $\beta$-actin was obtained from Sigma (MI, USA). Recombinant human (rh) TNF- $\alpha$ and rhIL-23 (R\&D Systems) was used for the stimulation of the cell lines.

Cell culture. Human oral squamous cell carcinoma (HOSCC: HSC-2, HSC-3, HSC-4 and Ca9-22) cells (obtained from the American Type Culture Collection, ATCC, Manassas, VA, USA) were respectively maintained in RPMI-1640 medium supplemented with $10 \%$ heat-inactivated fetal bovine serum (FBS), $100 \mathrm{IU} / \mathrm{ml}$ penicillin and $100 \mu \mathrm{g} / \mathrm{ml}$ streptomycin, and grown to confluency in $25 \mathrm{~cm}^{2}$ culture flasks at $37^{\circ} \mathrm{C}$ in a humidified $5 \% \mathrm{CO}_{2}$ incubator until use.

RNA extraction and RT-PCR. Total RNA was extracted from monolayer HOSCC cells $\left(1 \times 10^{6}\right.$ cells $\left./ \mathrm{ml}\right)$ by a previously reported acid-guanidinium-phenol-chloroform (AGPC) method (14). To confirm the expression of IL-23p19, IL-23R and IL-12R $\beta 1$ genes, RT-PCR analysis was performed. Briefly, random hexamer-primed single-stranded cDNA was synthesized with an RNA LA PCR ${ }^{\mathrm{TM}}$ Kit (Takara Shuzo, Shiga, Japan) from $1.0 \mu \mathrm{g}$ of total RNA in a final volume of $20 \mu \mathrm{l}$ with 0.25 units of avian myeloblastosis virus reverse transcriptase at $42^{\circ} \mathrm{C}$ for $60 \mathrm{~min}$. An aliquot $(1.0 \mu \mathrm{l})$ of the reaction mixture was diluted with $10 \mu \mathrm{l}$ of PCR buffer containing 4 pmole each of the forward and reverse primer sets. PCR primers were designed and synthesized by SigmaAldrich, Inc. (Ishikari, Japan). The following primer sequences were used in the PCR reactions: IL-23p19 forward: TGC TAG GAT CGG ATA TTT TCA CAG G; reverse: GAG GCT TGG AAT CTG CTG AGT C; IL-23R forward: GAT ATT CCT GAT GAA GTA ACC TGT GTC; reverse: GAT ACT GTT GCT CTT CTT CTG TCT C; IL-12R $\beta 1$ forward: TGT TTT CAG GAC CCG CCA TAT C; reverse: AAG GCA ACA CCG
CAG GAA G; GAPDH forward: CAG CCT CAA GAT CAT CAG CA; reverse: ACA GTC TTC TGG GTG GCA GT. The PCR reaction was then performed with 2.5 units of Takara LA $\mathrm{Taq}^{\mathrm{TM}}$ (Takara). The samples were subjected to denaturation at $94^{\circ} \mathrm{C}$ for $3 \mathrm{~min}$, followed by 40 cycles of denaturation at $94^{\circ} \mathrm{C}$ for $1 \mathrm{~min}$, annealing at $60^{\circ} \mathrm{C}$ for $2 \mathrm{~min}$ and extension at $72^{\circ} \mathrm{C}$ for $1 \mathrm{~min}$. The last cycle had an extension period of $7 \mathrm{~min}$. The amplified DNA was electrophoresed on a $2.0 \%$ agarose gel, stained with ethidium bromide and visualized on a UV illuminator, then photographed.

Cell proliferation assay. The cell proliferation assay used is based on the cleavage of the tetrazolium salt WST-8 to formazan by cellular mitochondrial dehydrogenases, the activity of which increases proportionally with the number of viable cells. The formazan dye produced by viable cells was quantified as an index of cell proliferation. Monolayer HSC-3 cells $\left(2 \times 10^{4}\right.$ cells $/ 100 \mu \mathrm{l} /$ well $)$ derived from lymph node metastasis of tongue cancer were incubated for $24 \mathrm{~h}$ on a 96-microwell plate. The cells were washed once with PBS and incubated with rhIL-23 (10 ng/ml) for 4, 8, 12, 24 and $48 \mathrm{~h}$ in RPMI-1640 medium with 10\% FBS. WST-8/ECS solution (10 $\mu \mathrm{l}$; Dojindo Laboratories, Tokyo, Japan) was added to each well and incubated with the cells for $2 \mathrm{~h}$ at $37^{\circ} \mathrm{C}$ in a humidified $5 \% \mathrm{CO}_{2}$ incubator. The cells were then shaken thoroughly for $1 \mathrm{~min}$ on a shaker. After shaking, the relative viable cell number was determined by measuring the absorbance of the dye solution at $450 \mathrm{~nm}$.

Immunoblot analysis. The monolayer cells $\left(1 \times 10^{6}\right.$ cells $\left./ \mathrm{ml}\right)$ were lysed in cell lysis buffer containing $50 \mathrm{mM}$ Tris- $\mathrm{HCl}$ (pH 8.0), $150 \mathrm{mM} \mathrm{NaCl}, 0.02 \%$ sodium azide, $1 \%$ Triton $\mathrm{X}-100,1 \mu \mathrm{g} / \mathrm{ml}$ aprotinin and $100 \mu \mathrm{g} / \mathrm{ml}$ phenylmethylsulfonyl fluoride (PMSF), and were scraped from the dishes with a cell scraper (Nalge Nunc, IL, USA). After $20 \mathrm{~min}$ on ice, the lysate was centrifuged for $5 \mathrm{~min}$ at $15,000 \mathrm{rpm}$ at $4^{\circ} \mathrm{C}$. The soluble supernatant fraction was used for Western blot analysis. Protein concentrations were measured using the Bio-Rad protein assay (Nippon Bio-Rad Laboratories, Tokyo, Japan). For the detection of IL-23, IL-23R and IL-12R $\beta 1$ protein by gel electrophoresis, $10-\mu \mathrm{g}$ protein samples were mixed with an equal volume of SDS-PAGE sample buffer and boiled for 5 min. These amounts were loaded per lane and separated on a polyacrylamide gel of appropriate percentage, then the proteins were electroblotted onto nitrocellulose membranes. Subsequent immunoblot analysis was carried out according to a previously reported method (14).

Primary tumor sample. A formalin-fixed paraffin-embedded specimen was obtained from a patient with SCC treated at the Department of Oral and Maxillofacial Surgery, Meikai University Hospital, Japan. The pathological diagnosis of the oral lesion was based on histological examination of H\&E-stained slides according to the WHO classification (15). Postsurgical TNM stage was determined according to the pTNM pathological classification of the International Union Against Cancer (UICC) (16). The specimens were obtained during surgical biopsy. The patient had not undergone preoperative chemotherapy or radiotherapy. For IL-23 and NF- $\kappa \mathrm{B}$ staining, the sections were immersed in absolute methanol 


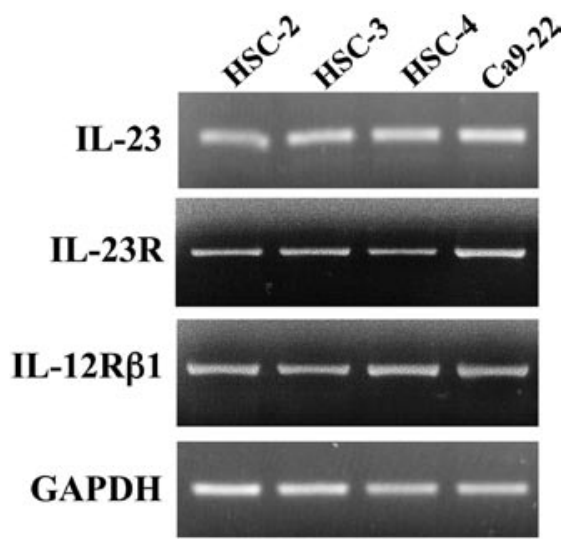

Figure 1. Expression of IL-23 and its receptor mRNAs in HOSCC cells analyzed by RT-PCR. The amplified fragment sizes were 143 bp for IL-23, $145 \mathrm{bp}$ for IL-23R and $156 \mathrm{bp}$ for IL-12R $\beta 1$. GAPDH mRNA detection was performed as an internal control, and revealed that the total RNA obtained was intact.

containing $0.3 \% \mathrm{H}_{2} \mathrm{O}_{2}$ for 20 min at room temperature to block endogenous peroxidase activity. After washing, each section was immersed in $0.01 \mathrm{M}$ citrate buffer ( $\mathrm{pH} \mathrm{6.0)}$ and heated in a microwave oven for $15 \mathrm{~min}$ as described by Shi et al (17). After washing with PBS (pH 7.4), the sections were incubated in $2 \%$ bovine serum albumin in PBS (BSA-PBS) for 15 min at room temperature to block non-specific reactions. Diluted PAb IL-23p19 (1:100) and MAb NF- $\kappa B ~(1: 100)$ were applied to the sections for $60 \mathrm{~min}$ at room temperature. After washing with PBS, the slides were incubated with rabbit anti-goat IgG $(\mathrm{H}+\mathrm{L})$ antibody for IL-23p19 (1:200) or horse anti-mouse IgG $(\mathrm{H}+\mathrm{L})$ antibody for $\mathrm{NF}-\mathrm{\kappa B}(1: 200)$ for $30 \mathrm{~min}$ at room temperature. Diluted streptavidin-peroxidase (1:1000) was applied to the sections for $30 \mathrm{~min}$. The sections were immersed for $10 \mathrm{~min}$ in $0.05 \%$ 3,3'-diaminobenzidine tetrahydrochloride in $0.05 \mathrm{M}$ Tris- $\mathrm{HCl}$ buffer ( $\mathrm{pH}$ 7.6) containing $0.01 \% \mathrm{H}_{2} \mathrm{O}_{2}$, and then counterstained with Mayer's haematoxylin.

Ethical considerations. The study was approved by the Research Ethics Committee of the Meikai University School of Dentistry.

\section{Results}

Detection of the gene expression IL-23 and its receptors in HOSCC cells stimulated by TNF- $\alpha$. To investigate whether the HOSCC (HSC-2, HSC-3, HSC-4 and Ca9-22) cell cultures expressed IL-23 and its receptor mRNAs, RT-PCR analysis was carried out using specifically designed primer pairs. The expression of IL-23 was detected in the total RNA of each oral tumor cell line (Fig. 1). As an internal control, GAPDH mRNA detection was performed to assess the integrity of the cDNA obtained from the total RNA extracted from the oral tumor cell lines, thus demonstrating that the total RNA obtained was intact. The IL-23R and IL-12R $\beta 1$ receptors were detected in four HOSCC cell lines (Fig. 1).

Protein expression of heterodimeric IL-23 and its receptors in HOSCC cells. SDS-solubilized cell extracts of the HOSCC cell lines were subjected to immunoblot analysis to determine the presence of IL-23 and its receptor proteins, as well
A

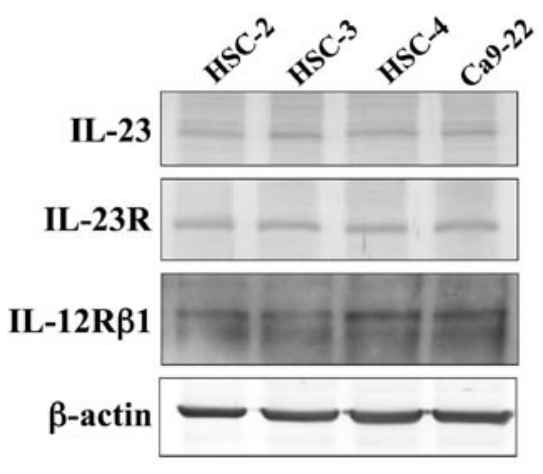

B

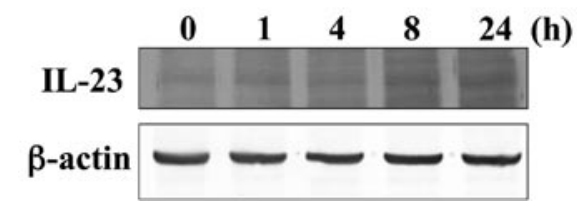

Figure 2. Immunoblot analysis. (A) Immunoblotting revealed that the IL-23, IL-23R and IL-12R $\beta 1$ induced in the HOSCC cell lines were the $21-\mathrm{kDa}$, 69-kDa and 75-kDa peptides, respectively, and were spontaneously expressed. (B) IL-23 protein in HSC-3 cells was markedly increased by TNF- $\alpha$ treatment in a time-dependent manner.

as the quantity of these proteins expressed in HOSCC cells. Immunoblot analysis revealed that the IL-23, IL-23R and IL-12R $\beta 1$ induced in the HOSCC cell lines were the $21-\mathrm{kDa}$, 69-kDa and 75-kDa peptides, respectively (Fig. 2A). Therefore, IL-23 and its receptor peptides were endogenously expressed in the HOSCC cell lines. The effect of TNF- $\alpha$ on the level of IL-23 protein was then determined by treating HSC-3 cells with $10 \mathrm{ng} / \mathrm{ml} \mathrm{TNF}-\alpha$ over a time course (Fig. $2 \mathrm{~B}$ ). TNF- $\alpha$ induced a gradual increase in the level of IL-23 protein in a time-dependent manner.

Increase in the number of HSC-3 cells by IL-23. To investigate whether IL-23 promotes cell proliferation in HOSCC, a cell proliferation assay was carried out using the HSC-3 cell line. HSC-3 cell numbers were revealed to be distinctly increased in a time-dependent manner by treatment with $10 \mathrm{ng} / \mathrm{ml}$ of rhIL-23; treatment with $10 \mathrm{ng} / \mathrm{ml}$ of rhIL-23 produced an $\sim 5$-fold increase in the number of HOSCC cells during the 2-day culture (Fig. 3). The cell number after $48 \mathrm{~h}$ of treatment with rhIL-23 was increased 2-fold in comparison with the untreated control. HSC-3 cells were further treated with IL-23 in the presence of PAb IL-23p19, a neutralizing antibody specific for IL-23 (Fig. 3). PAb IL-23p19 abolished the induction of cell proliferation by IL-23, and the HSC-3 cell number was ultimately reduced to the control level. This result indicates that the promotion of cell proliferation is a specific effect of IL-23 in HOSCC.

Immunohistochemical detection of $I L-23$ and $N F-\kappa B$ in SCC tissue. Immunohistochemical detection of IL-23 and NF- $\kappa \mathrm{B}$ was carried out in a patient with oral SCC. A positive reaction for PAb IL-23 was weakly observed in the cytoplasm of infiltrating inflammatory cells and cancer cells in SCC tissue. In contrast, strong RelA immunoreactivity was observed, especially consistent with IL-23-positive cells in SCC tissue (Fig. 4). 


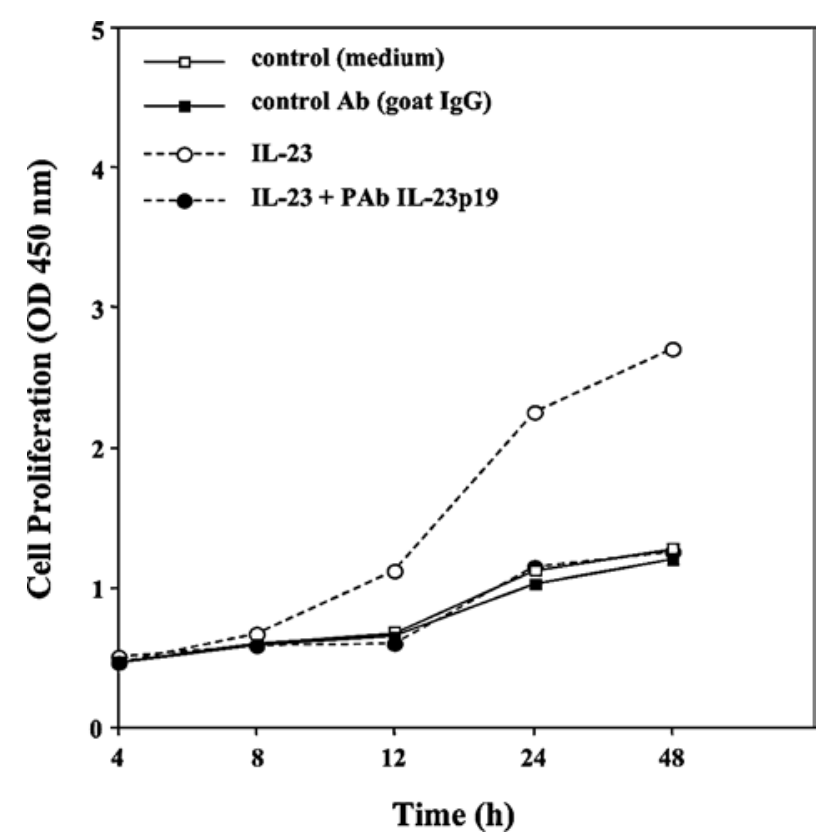

Figure 3. Cell proliferation assay. The cell proliferation assay indicated that HSC-3 cell numbers were distinctly increased in a time-dependent manner after treatment with $10 \mathrm{ng} / \mathrm{ml}$ of rhIL-23; treatment with $10 \mathrm{ng} / \mathrm{ml}$ of rhIL-23 produced an $\sim 5$-fold increase in the number of HSC-3 cells during the 2-day culture. The cell number after $48 \mathrm{~h}$ of treatment with rhIL-23 was increased 2-fold in comparison with the untreated control. Furthermore, PAb IL-23p19, a neutralizing antibody specific for IL-23, abolished the induction of cell proliferation by IL-23, and the HSC-3 cell number was ultimately reduced to the control level.
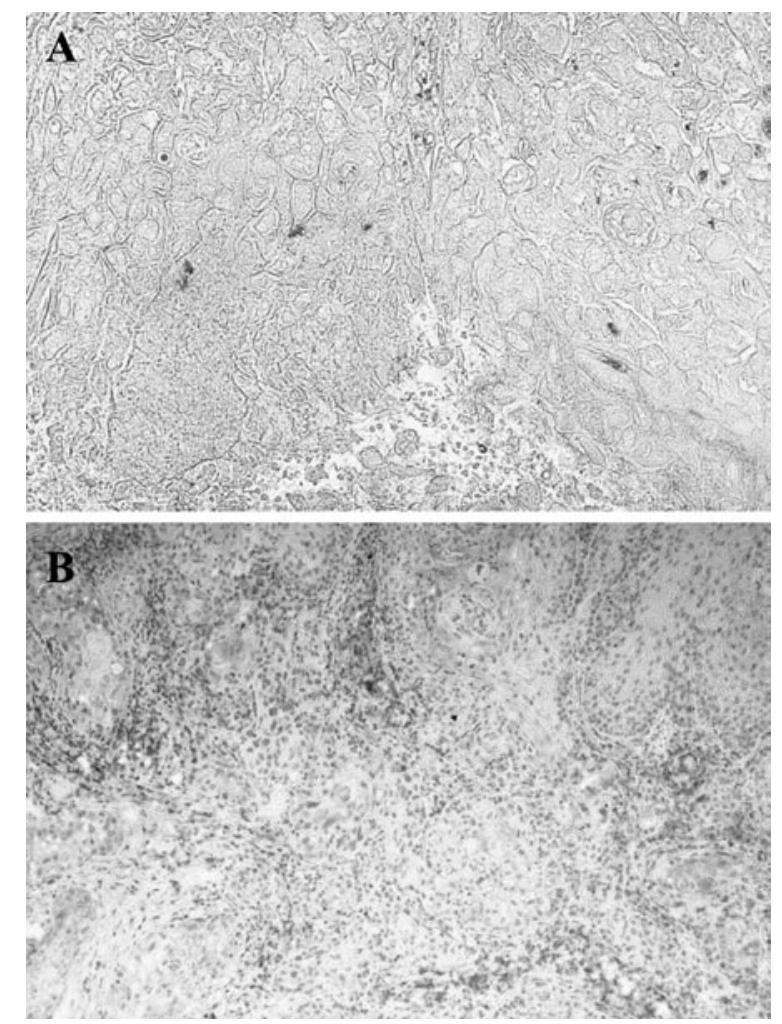

Figure 4. Immunohistochemistry. Immunohistochemical detection of IL-23 and $\mathrm{NF}-\kappa \mathrm{B}$ was carried out in a patient with oral SCC. (A) A positive reaction for PAb IL-23 was weakly observed in the cytoplasm of inflammatory infiltrating cells and cancer cells. (B) A strong positive reaction with MAb RelA was observed in the cytoplasm of cancer cells, particularly consistent with the observation of IL-23-positive cells in SCC tissue. Magnification x66.

\section{Discussion}

The expression of cytokines and their receptors in human tumors has attracted a great deal of interest due to their potential significance for tumor immunity. In particular, it has previously been reported that members of the TNF family including Fas/ Fas ligand and TRAIL regulate the elimination of unwanted immune cells by inducing apoptosis (18-20). However, despite the expression of these distinct antigens, tumor elimination by the immune system is often inefficient. It is thought that tumor cells may also evade immune attack by expressing Fas ligand, TRAIL or other molecules that induce apoptosis in activated T cells (21). In addition, we observed in a previous study that tumor cells possess the potential to escape immune surveillance by killing host $\mathrm{T}$ lymphocytes through several cytokines, such as RCAS1 (22). In a more recent study, IL-23 was identified as a cancer-associated cytokine. The expression of IL-23, but not that of its close relative IL-12, was significantly increased in the vast majority of human tumors from various organs as compared with normal adjacent tissue from the same individuals (13). The role of IL-23 in tumorigenesis is clearly demonstrated in mice lacking IL-23p19; these mice are almost completely resistant to endogenous tumor formation when challenged in a chemical carcinogenesis protocol (13). By comparison, a sizeable number of reports have described the tumor-inhibitory effects of IL-23 in fast growing, immune-sensitive mouse tumor models genetically engineered to overexpress an IL-23-like product with linked p40 and p19 subunits. Following implantation in immune-naive hosts, IL-23-overexpressing tumors show reduced growth and metastasis, consistent with the stimulation of a CD8-positive memory T-cell response (23-27). As mentioned, the precise role of IL-23 and its function at the cancer invasive front is controversial. Although a variety of tissues have been screened and found to be positive for IL-23 expression, no data exist regarding whether IL-23 is expressed in the oral region.

In the present study, we demonstrated that the mRNA and protein levels of IL-23 and its receptors were constitutively co-expressed in HOSCC cells, and that IL-23 was increased by TNF- $\alpha$ stimulation in HSC-3 cells in a time-dependent manner. Blocking the function of IL-23 inhibited the proliferative activity of tumor cells. Furthermore, the in vivo experiments revealed strong RelA-specific immunoreactivity in an SCC biopsy sample, particularly consistent with the observation of IL-23-positive cells in SCC tissue. NF- $\kappa B$ plays key roles in inflammation, immune response, tumorigenesis and protection against apoptosis (28-30). In most cell types, NF- $\kappa \mathrm{B}$ remains bound to I $\mathrm{KB} \alpha$ protein, and thereby inactive, in the cytoplasm $(31,32)$. After stimulation by various reagents, I $\mathrm{I} \mathrm{B} \alpha$ is rapidly phosphorylated by the IкB kinase (IKK) complex and degraded by the proteasome, allowing NF- $\mathrm{KB}$ to translocate to the nucleus and activate its target gene $(29,33,34)$. Here, we suggested that IL-23 might promote NF- $\kappa \mathrm{B}$ activity, or alternatively that IL-23 function might be activated by NF- $\mathrm{NB}$ in SCC tissue. Finally, we noted that IL-23 was secreted not only by DCs and macrophages, as shown in previous studies (4), but also by autologous cancer cells. Consequently, we propose the existence of an autocrine mechanism, by which tumor growth is promoted by IL-23 produced by autologous cancer cells. The combined data indicate that IL-23 plays a 
significant role in the growth and proliferation of oral cancer; thus, IL-23 could be used as a predictor of poor prognosis in patients with the disease. Identification of the signaling pathways underlying these events may provide the key to elucidating the mechanisms of the development of oral cancer. Further investigation into the role of IL-23 is required to fully understand IL-23-mediated tumor survival and to establish an IL-23-based oral cancer therapeutic strategy.

\section{Acknowledgements}

This study was supported by a Grant-in-Aid for scientific research from Meikai University.

\section{References}

1. Coussens LM and Werb Z: Inflammation and cancer. Nature 420: 860-867, 2002.

2. Balkwill F, Charles KA and Mantovani A: Smoldering and polarized inflammation in the initiation and promotion of malignant disease. Cancer Cell 7: 211-217, 2005.

3. Zha S, Yegnasubramanian V, Nelson WG, Isaacs WB and De Marzo AM: Cyclooxygenases in cancer: progress and perspective. Cancer Lett 215: 1-20, 2004.

4. Oppmann B, Lesley R, Blom B, et al: Novel p19 protein engages IL-12p40 to form a cytokine, IL-23, with biological activities similar as well as distinct from IL-12. Immunity 13: 715-725, 2000.

5. Sospedra M and Martin R: Immunology of multiple sclerosis. Ann Rev Immunol 23: 683-747, 2005.

6. Parham C, Chirica M, Timans J, et al: A receptor for the heterodimeric cytokine IL-23 is composed of IL-12Rbeta1 and a novel cytokine receptor subunit, IL-23R. J Immunol 168: 5699-5708, 2002.

7. Lankford CSR and Frucht DM: A unique role for IL-23 in promoting cellular immunity. J Leukocyte Biol 73: 49-56, 2003.

8. Brunda MJ, Luistro L, Warrier RR, et al: Antitumor and antimetastatic activity of interleukin 12 against murine tumors. J Exp Med 178: 1223-1230, 1993.

9. Nastala CL, Edington HD, McKinney TG, et al: Recombinant IL-12 administration induces tumor regression in association with IFN-production. J Immunol 153: 1697-1706, 1994

10. Cua DJ, Sherlock J, Chen Y, et al: Interleukin-23 rather than interleukin-12 is the critical cytokine for autoimmune inflammation of the brain. Nature 421: 744-748, 2003.

11. Murphy CA, Langrish CL, Chen Y, et al: Divergent pro- and anti-inflammatory roles for IL-23 and IL-12 in joint autoimmune inflammation. J Exp Med 198: 1951-1957, 2003.

12. Becher B, Durell BG and Noelle RJ: IL-23 produced by CNS-resident cells controls $T$ cell encephalitogenicity during the effector phase of experimental autoimmune encephalomyelitis. J Clin Invest 112: 1186-1191, 2003.

13. Langowski JL, Zhang X, Wu L, et al: IL-23 promotes tumour incidence and growth. Nature 27: 461-465, 2006.

14. Fukuda M, Horiuchi Y, Oku Y, et al: Induction of apoptosis in human salivary gland tumor cells by anti-NCAM antibody. Oncol Rep 14: 1143-1149, 2005.
15. Pindborg JJ, Reichart PA, Smith CJ and van der Waal I: Histological typing of cancer and precancer of the oral mucosa. World Health Organization International histological Classification of tumors. 2nd edition. Springer-Verlag, Berlin, Heidelberg, New York, pp11-38, 1997.

16. UICC TNM classification of malignant tumors. Sobin LH and Wittekind CH (eds). 5th edition. John Wiley and Sons Inc., New York, pp20-24, 2002.

17. Shi SR, Key ME and Kalra KL: Antigen retrieval in formalinfixed and paraffin-embedded tissues: an enhancement method for immunohistochemical staining based on microwave oven heating of tissue sections. J Histochem Cytochem 39: 741-748, 1991.

18. Nagata S: Apoptosis by death factor. Cell 88: 355-365, 1997.

19. Wiley SR, Schooley K, Smolak PJ, et al: Identification and characterization of a new member of the TNF family that induces apoptosis. Immunity 3: 673-682, 1995.

20. Pitti RM, Marsters SA, Ruppert S, Donahue CJ, Moore A and Ashkenazi A: Induction of apoptosis by Apo-2 ligand, a new member of the tumor necrosis factor cytokine family. J Biol Chem 271: 12687-12690, 1996.

21. Nakashima M, Sonoda $K$ and Watanabe $T$ : Inhibition of cell growth and induction of apoptotic cell death by the human tumor-associated antigen RCAS1. Nat Med 5: 938-942, 1999.

22. Fukuda M, Tanaka A, Hamao A, Suzuki S, Kusama K and Sakashita H: Expression of RCAS1 and its function in human squamous cell carcinoma of the oral cavity. Oncol Rep 12: 259-267, 2004.

23. Shimozato O, Ugai S, Chiyo M, et al: The secreted form of the p40 subunit of interleukin (IL)-12 inhibits IL-23 functions and abrogates IL-23-mediated antitumour effects. Immunology 117 : 22-28, 2006

24. Shan BE, Hao JS, Li QX and Tagawa M: Antitumor activity and immune enhancement of murine interleukin-23 expressed in murine colon carcinoma cells. Cell Mol Immunol 3: 47-52, 2006.

25. Shan B, Yu L, Shimozato O, Li Q and Tagawa M: Expression of interleukin-21 and -23 in human esophageal tumors produced antitumor effects in nude mice. Anticancer Res 24: 79-82, 2004.

26. Lo CH, Lee SC, Wu PY, et al: Antitumor and antimetastatic activity of IL-23. J Immunol 171: 600-607, 2003.

27. Overwijk WW: Breaking tolerance in cancer immunotherapy: time to ACT. Curr Opin Immunol 17: 187-194, 2005.

28. Li Q and Verma IM: NF-kappaB regulation in the immune system. Nat Rev Immunol 2: 725-734, 2002.

29. Karin M, Cao Y, Greten FR and Li ZW: NF- $\kappa B$ in cancer: from innocent bystander to major culprit. Nat Rev Cancer 2: 301-310, 2002.

30. Orlowski RZ and Baldwin AS Jr: NF-kappaB as a therapeutic target in cancer. Trends Mol Med 8: 385-389, 2002.

31. Baeuerle PA and Baltimore D: I kappaB: a specific inhibitor of the NF-kappaB transcription factor. Science 242: 540-546, 1988.

32. Rodriguez MS, Thompson J, Hay RT and Dargemont C: Nuclear retention of $\mathrm{I} \kappa \mathrm{B} \alpha$ protects it from signal-induced degradation and inhibits nuclear factor $\mathrm{\kappa B}$ transcriptional activation. J Biol Chem 274: 9108-9115, 1999.

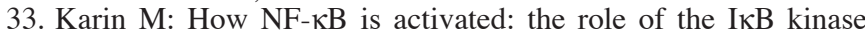
(IKK) complex. Oncogene 18: 6867-6874, 1999.

34. Smahi A, Courtois G, Rabia SH, et al: The NF-kappaB signalling pathway in human diseases: from incontinentia pigmenti to ectodermal dysplasias and immune-deficiency syndromes. Hum Mol Genet 11: 2371-2375, 2002. 